AARON PRESTON

\title{
QUALITY INSTANCES AND THE STRUCTURE OF THE CONCRETE PARTICULAR
}

\begin{abstract}
In this paper, I examine a puzzle that emerges from what J. P. Moreland has called the traditional realist view of quality instances. Briefly put, the puzzle is to figure out how quality instances fit into the overall structure of a concrete particular, given that the traditional realist view of quality instances prima facie seems incompatible with what might be called the traditional realist view of concrete particulars. After having discussed the traditional realist views involved and the puzzle that emerges from their juxtaposition, I propose an alternative realist view of quality instances which resolves the puzzle. In short, the puzzle is solved by treating the distinction between a concrete particular and its quality instances as a distinction of reason, and by adopting the view that the individuating element of a concrete particular must also serve as its unifying element - a view which Moreland, one of traditional realism's most stalwart contemporary defenders, rejects.
\end{abstract}

KEY WORDS: abstract particulars, concrete particulars, J. P. Moreland, ontology, part-whole relation, properties, quality instances, realism, universals

The notion of a quality instance belongs to the ontology of concrete particulars. A concrete particular is the same as what is sometimes called an Aristotelian substance - for example, this man, this horse, and so on. In the context of a constituent ontology, a concrete particular is commonly analyzed into an individuating element (for example, a bare particular), a set of qualities (a.k.a. "attributes," "properties"), and a set of exemplification (a.k.a. "predication," "instantiation") relations, each of which obtains between the individuator and one of the qualities. One begins to speak of quality instances in cases of attribute agreement, cases in which multiple concrete particulars appear to have the same quality - e.g., two stoplights appear to have the same color, red. Here we speak of multiple instances of the quality Red. ${ }^{1}$

In general, there are two standard ways of dealing with attribute agreement: (1) to accept the appearance as reality, and thus to accept 
that qualities are universals, or (2) to deny that there is a literal identity of quality, and to explain the appearance by, e.g., claiming that a relation of exact similarity obtains between the multiple instances. ${ }^{2}$ Views consistent with the first approach are commonly called realist views of qualities (or quality instances), as they involve realism about universals. The traditional realist view of quality instances (so-called by J. P. Moreland), which is to be our target here, is one type of realist view. This view has a long history. ${ }^{3}$ Proponents of the view usually draw their inspiration from Aristotle and the Aristotelian tradition. ${ }^{4}$ In modern times, versions of it have been defended by members of the Brentano school including (on one interpretation) Edmund Husserl. ${ }^{5}$ In the early 20th century, aspects of the traditional realist view were the subject of a well-known exchange between G. E. Moore and G. F. Stout. ${ }^{6}$ In the latter half of that century, realist views of quality instances were defended by such luminaries as Gustav Bergmann, Edwin Allaire, and David Armstrong. ${ }^{7}$ In recent years, few have written as much in favor of this view as J. P. Moreland. In what follows, I shall focus exclusively upon Moreland's formulation of the traditional realist position.

According to Moreland, the traditional realist view is that "quality instances [are] complex entities with their natures in them as constituents. $" 8$ To illustrate the view, he sets up a case of attribute agreement between two red, round spots, which he names Socrates and Plato, respectively. Socrates and Plato are supposed to have the same shade of red, and the same round shape. The core of the traditional realist view of quality instances, according to Moreland, is the appeal to universals in explanation of the apparent sameness involved in attribute agreement. ${ }^{9}$ Thus, within the traditional realist view of quality instances, Moreland subscribes to what he calls the traditional realist view of universals, according to which universals are non-spatiotemporal abstract entities which are literally in their instances (in some non-spatiotemporal sense of "in") by means of a primitive relation (also non-spatiotemporal) which Moreland usually calls predication, but which is also known as exemplification or instantiation. Thus, "when Socrates is red, Socrates has the universal redness in it. Redness is literally in Socrates as a constituent." 10 Presumably the same is true for Plato. Thus, on the traditional realist view of quality instances, Socrates and Plato share a constituent - the universal Red.

However, there must be some distinction between redness-inSocrates and redness-in-Plato. This is made clear by, among other 
things, the phenomenon of selective destructability: ${ }^{11}$ e.g., Socrates' redness can be destroyed without affecting Plato's redness, and vice versa. Some have taken the selective destructability of quality instances as evidence that qualities are not universals, since, if Socrates' red and Plato's red are one and the same entity, then one could not survive the destruction of the other. ${ }^{12}$ However, Moreland claims that the traditional realist view of quality instances can account for the difference between the redness of Socrates (which he calls red $_{1}$ ) and the redness of Plato (which he calls $\mathrm{red}_{2}$ ) without rejecting universals. For the traditional realist, the complex structure of a quality instance includes not only a universal and a predication relation but also an individuator. ${ }^{13}$ Moreland's individuator-of-choice is the bare particular. Hence, presumably, the ontological structure of a Morelandian quality instance can be represented thus:

$$
\mathrm{U}_{1} \longrightarrow \mathrm{P}_{1}
$$

where $\mathrm{U}_{1}=$ a universal such as Red; $\mathrm{P}_{1}=$ a bare particular; and the line $=$ a predication relation. For any two quality instances belonging to two numerically different concrete particulars (such as red $_{1}$ and $\left.\operatorname{red}_{2}\right)$, it is possible that they will involve the same universal as a constituent, but the predication relations and bare particulars involved will always be numerically different. Thus, since Socrates' redness is to be understood as a state-of-affairs consisting in the universal Red being predicated of a bare particular, and since the bare particular and the predication relation are unique constituents of Socrates - that is, they belong to no other concrete particular (at least while they belong to Socrates) - we can understand the destruction of Socrates' redness in terms of the dissolution of the predication relation between the universal Red and the bare particular in red $_{1}$. This allows the traditional realist to maintain the existence of universals in the face of the obvious difference between the redness of Socrates and the redness of Plato.

At the outset of Section 1, it was suggested that a concrete particular, like a traditional realist quality instance, is to be analyzed into an individuator, a set of qualities, and a set of binding relations. This might be called the traditional realist view of concrete particulars. This seems to be the way E. B. Allaire, for one, analyzes concrete particulars: 
Consider "this is red" asserted truly of a colored disc. Some philosophers claim that the sentence refers to a fact consisting of two (kinds of) entities, an individual (bare particular), and a character (universal), referred to by "this" and "red", respectively. They claim further that the two entities stand in the exemplification relation, represented by "is." 14

It seems clear that, for Allaire, the structure of the concrete particular involves one bare particular, which provides for its thisness or thatness, that is, its particularity.

Moreland, too, makes a number of statements which seem to fit this analysis of concrete particulars. For example, in the context of the Socrates-Plato case discussed in Section 1, he explicitly includes himself among those who would assay a concrete particular like Socrates or Plato in terms of universals related to an individuator by means of predication relations:

Socrates and Plato each have the same, numerically identical nature - redness - as a constituent in each, as well as an individuator (perhaps, a bare particular), and a part-whole relation, the tie of predication between redness and the bare particular in each. $^{15}$

The language here suggests that each concrete particular has but one individuator. Elsewhere, in language reminiscent of Allaire, Moreland says that "bare particulars constitute the 'this' and the 'that' of Plato and [another concrete particular] Aristotle."16 Again, this seems to indicate that there is but one individuator per concrete particular - otherwise Socrates would be a these instead of a this. These statements suggest that the ontological structure of Moreland's Socrates can be represented thus:

$$
\mathrm{U}_{1}-\mathrm{P}_{1}-\mathrm{U}_{2}
$$

where $\mathrm{P}_{1}=$ the bare particular in Socrates; $\mathrm{U}_{1}=$ the universal Red; $\mathrm{U}_{2}=$ the universal Round, and lines $=$ ties of predication. I'll call this Analysis 1.

However, Moreland's account of the traditional realist view of quality instances suggests a different analysis for concrete particulars. Though, as we have seen, Moreland agrees that concrete particulars have universals in them as constituents via the tie of predication, which he characterizes as a part-whole relation, Moreland further analyzes the presence of a universal in a concrete particular thus:

when "Socrates is red" is true, it is because some individuating entity "in" Socrates (where "in" here is to be read as "is a constituent of" and taken as a primitive) 
exemplifies redness. When Socrates is red, this is to be analyzed as follows: a quality instance, moment, etc., that is "predicatively" red, is a part of the whole, Socrates. ${ }^{17}$

The second of these sentences seems simply to reiterate the point made in the first. If this is so, then there are some important differences between the traditional realist view of the concrete particular and the view expressed here. Most notably, instead of having the predication relation obtain between the solitary bare particular in Socrates and the universal Red, it now obtains only within the quality instance - only it is "predicatively" red; moreover, given the assay of a Morlandian quality instance presented in Section 1, we can suppose that the predication relation obtains between the bare particular in $\operatorname{red}_{1}$ and the universal Red. The quality instance - in itself a certain sort of whole - is then folded into the larger whole, Socrates, not by predication but by a primitive phenomenon which Moreland calls "being in" or "being a constituent of", and which he construes as a kind of part-whole relation. ${ }^{18}$ Thus, taken together with what was said about the structure of traditional realist quality instances in Section 1, the view expressed here seems to be that a universal $\mathrm{U}$ is literally in a concrete particular $\mathrm{C}$ as a constituent of it; but $\mathrm{U}$ is a constituent of $\mathrm{C}$ only in virtue of U's being predicated of a bare particular $\mathrm{P}$ in/which is a constituent of a quality instance $\mathrm{Q}$, and Q's being a constituent of $\mathrm{C}$. It seems, therefore, that the ontological structure of Socrates should be represented thus:

$$
\left\{\left(\mathrm{U}_{1}-\mathrm{P}_{1}\right) \quad\left(\mathrm{P}_{2}-\mathrm{U}_{2}\right)\right\}
$$

where $\mathrm{P}_{1}$ and $\mathrm{P}_{2}=$ bare particulars in Socrates; $\mathrm{U}_{1}=$ the universal Red, $\mathrm{U}_{2}=$ the universal Round; solid lines = ties of predication; and the brackets indicate the scope of the in-ness/constitution relation, which here encompasses quality instances $\operatorname{red}_{1}\left(\mathrm{U}_{1}-\mathrm{P}_{1}\right)$ and $\operatorname{round}_{1}$ $\left(\mathrm{U}_{2}-\mathrm{P}_{2}\right)$, thus folding them into the whole, Socrates. ${ }^{19}$ I will call this Analysis 2.

The puzzle now emerges. On Analysis 1, the concrete particular consists in universals predicated of a bare particular, while on Analysis 2 it consists in a number of quality instances, each of which consists in a universal predicated of a bare particular, held together by some mysterious bond - not the relation of predication - which makes them parts of a whole. Thoroughgoing traditional realists of Moreland's ilk seem to subscribe to both views - we have certainly seen statements which indicate that Moreland does. Thus the puzzle is to figure out how Analyses 1 and 2 fit together. If they cannot be 
combined in a satisfactory way, it seems that the thoroughgoing traditional realist is in trouble.

It might occur to one simply to combine Analyses 1 and 2, so that Socrates would be represented thus:

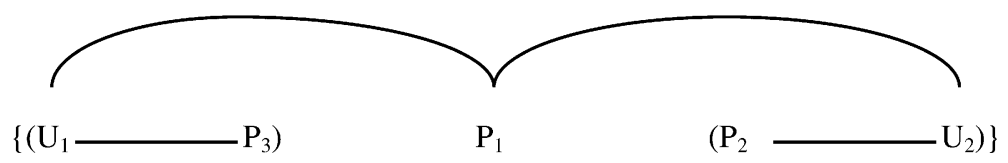

where $\mathrm{P}_{1-3}=$ bare particulars; $\mathrm{U}_{1}$ and $\mathrm{U}_{2}=$ the universals Red and Round, respectively; and solid lines $=$ ties of predication. The brackets indicate the scope of the in-ness/constitution relation, which here encompasses quality instances $\operatorname{red}_{1}\left(\mathrm{U}_{1}-\mathrm{P}_{1}\right)$ and $\operatorname{round}_{1}\left(\mathrm{U}_{2}-\mathrm{P}_{2}\right)$ along with bare particular $\mathrm{P}_{1}$, thus folding them into the whole, Socrates. I'll call this Analysis 3.

There are two problems with Analysis 3. First, it creates redundancies within the structure of the concrete particular. According to Analysis 1 the bare particular $\mathrm{P}_{1}$ is sufficient to account for the thisness of Socrates, while on Analysis 2 the in-ness/constitution relation is supposed to account for it. Thus, to combine both ways of accounting for the thisness of Socrates is redundant. Likewise, on Analysis 1 the predication relation which obtains between $\mathrm{P}_{1}$ and the universals $\mathrm{U}_{1}$ and $\mathrm{U}_{2}$ is sufficient to account for Socrates' being red and round, while on Analysis 2 the facts that (1) $U_{2}$ and $U_{1}$ are predicated of $\mathrm{P}_{2}$ and $\mathrm{P}_{3}$, respectively, thus forming quality instances $\operatorname{red}_{1}$ and round $_{1}$, and that (2) red $_{1}$ and round ${ }_{1}$ are constituents of Socrates, are sufficient to account for it. Thus to combine these two ways of accounting for Socrates' being $x$ is redundant. While redundancy is not a world-ending problem, it is undesirable; thus any analysis which incorporates all the elements of Analyses 1 and 2 without the redundancies of Analysis 3 will be preferable as a solution to the puzzle. The second problem is that there is little support to be found for Analysis 3 in immediate experience. That is, Analysis 3 is not a natural position to arrive at merely by considering how best to analyze concrete particulars. Rather, it seems merely to be an ad hoc device which is thrown up in the face of the puzzle. It is preferable to have an analysis which might emerge naturally from the direct attempt to analyze concrete particulars, rather than from the direct attempt to solve the puzzle.

Another possibility, which seems the better one, is to treat each quality instance of Socrates-on-Analysis 2 as sharing one and the same bare particular, namely, that bare particular which serves as the 
thisness of Socrates-on-Analysis 1. For example, in Analysis 3, $\mathrm{P}_{2}$ and $\mathrm{P}_{3}$ are to be made identical to $\mathrm{P}_{1}$. I'll call this Analysis 4 . In addition to eliminating the extraneous bare particulars of Analysis 3, Analysis 4 makes the predication relation between a universal and the bare particular of a quality instance numerically identical to the predication relation between that universal and the bare particular of the concrete particular to which that quality instance belongs. In this way, the redundancies of Analysis 3 are eliminated, and both traditional realist views are preserved. Socrates, on this view, could be represented either as it was on Analysis 1, or, if one was interested in displaying Socrates' quality instances, thus:

$$
\left(\mathrm{U}_{1}-\left[\mathrm{P}_{1}\right)-\mathrm{U}_{2}\right]
$$

where the boundaries of quality instances red $_{1}$ and round ${ }_{1}$ are indicated by parentheses and square brackets, respectively. ${ }^{20}$

So far, Analysis 4 has, without redundancy, accounted for every element in Analyses 1 and 2 except for the part-whole (in-ness/constitution) relation which figures in Analysis 2. And here I propose that the best way to handle this is to treat the part-whole relation as an apparent relation only - that is, one that does not exist in reality and that, therefore, it need not be represented in an adequate analysis of a concrete particular. Before I explain this proposal, however, let us examine Moreland's view of the matter more closely.

Essentially, the puzzle arises from the fact that traditional realist quality instances seem prima facie to be "little" concrete particulars. ${ }^{21}$ They are concrete particulars in that they seem to share the concrete particular's basic ontological structure: both are property-individuator complexes bound by predication. They are "little" in that a given quality instance involves but one property whereas a full-blown concrete particular will usually have a multitude of properties. It may be helpful to relate the notion of a "little" concrete particular to some well-established terminology in contemporary ontology. Armstrong has coined the terms "thin particular" and "thick particular" to refer to substance-as-bare-substrate and substance-as-concrete-particular, respectively. ${ }^{22} \mathrm{~A}$ traditional realist quality instance is not a thin particular. It is a substrate with a property, and hence a concrete or "thick" particular. Still, insofar as it has far fewer properties, it is a good bit thinner than any standard example of a thick particular. To distinguish between these two types of thick particular we can call traditional realist quality instances "thinner particulars" and more standard examples of thick particulars "thicker particulars." 
According to Analyses 2 and 3, a thicker particular must be regarded as (at least in part) an aggregate of thinner particulars; but, since these analyses present each quality instance as having its own unique individuator, the thicker particular would seem to be a these, rather than a this. Moreland, though, clearly rejects the aggregate view of thicker particulars:

Fido [a dog, and hence a concrete particular] is a deeper unity of properties than say, a heap of salt is. Such a heap would be a unity of whiteness and the heap's shape. But such a whole, though a true unity of these properties, is not as deep a unity as is Fido. In fact, the heap's unity is derived from or emergent upon a collection of previously existing parts brought together in certain ways. Fido's properties are much more intimately related to one another than are the properties of lesser unities like heaps of parts. $^{23}$

A heap of salt may be regarded as a unified whole or as an aggregate of parts, as a this or a these, as it suits us. Its actual ontology does not dictate one way or the other. However, on Moreland's view, it is incorrect to treat a concrete particular like Fido as mere aggregate indeed, it would seem perverse to do so. The reason, according to Moreland, is the "deeper unity" present among Fido's constituents (parts, properties, capacities). But what accounts for this deeper unity? Nothing other than the mysterious part-whole/in-ness/constitution relation.

Much seems to turn on the nature of this relation. Unfortunately, Moreland's understanding of it is difficult to decipher. On the one hand, he insists that "the unity of properties (parts, capacities) in Fido is primitive," 24 that "a substance is a primitive unity of properties, parts, and capacities." ${ }^{25}$ Normally a primitive is something that cannot be further analyzed or explained. Nonetheless, on the other hand, Moreland says:

Properties adhere together in substances: they are united together. What explains this fact? The traditional view says that adherence is explained by inherence. All of Fido's properties adhere because they are owned by (or inhere in) the same substance that stands under them. ${ }^{26}$

It is unclear how the unity of Fido's properties can be both primitive and explained by the phenomenon of inherence. Perhaps Moreland means to say that the why of adherence or unity (i.e., why are just these properties arranged just so?) is primitive, but that the how (i.e., how is it that these properties "hang together" here?) is explicable in terms of inherence. If so, then it would seem that, in the above passage, 
Moreland is using "substance" in two different senses. When he says that "properties adhere together in substances" he would seem to have in mind what is sometimes called a Categories substance (as in Aristotle's Categories), which is the same as a thicker particular. However, when he says that "all of Fido's properties adhere [i.e., are unified] because they are owned by (or inhere in) the same substance that stands under them" he would seem to have in mind a substrate such as Armstrong's thin particular, the likes of which Aristotle discusses in his investigation into primary substance in the Metaphysics. One of the things a Metaphysics primary substance is supposed to do is individuate the concrete particular of which it is a constituent, and we have already seen that Moreland's preferred individuator is the bare particular; thus, on this interpretation, the claim that "all of Fido's properties adhere [i.e., are unified] because they are owned by (or inhere in) the same substance that stands under them" would amount to the claim that Fido is unified by his bare particular. However, Moreland explicitly denies that bare particulars serve as unifiers - they are, for him, as they were for Bergmann, individuators only. ${ }^{27}$ So perhaps he does not intend the second instance of "substance," above, to refer to the bare particular in Fido. Perhaps he means to use "substance" in the sense of "concrete particular" in both instances. In this case, Moreland's statement would amount to the claim that the unity of properties in the concrete particular, Fido, is explained by their inherence in the concrete particular, Fido. In other words, these properties are unified in the way they are because they belong to one and the same concrete particular, and concrete particulars simply have this kind of unity as a primitive, unanalyzable fact. In light of the initial question - what brings these properties together in such a way as to form a concrete particular, rather than a heap or aggregate? - this is not much of an explanation, for it says nothing more than that these properties are together in such a way that they constitute a concrete particular because they belong to the same concrete particular. But perhaps this is what Moreland means by saying that the unity of a concrete particular is primitive.

Let us see whether greater light can be shed on Moreland's views by examining an important distinction made in his most recent work on universals. ${ }^{28}$ Recall that the puzzle arises from the fact that quality instances apparently have the same basic ontological structure as concrete particulars - they are both property-individuator complexes bound by predication. Here, however, Moreland explicitly treats quality instances and concrete particulars as generically different in 
terms of their ontological structure. Consider the states-of-affairs described by the sentences:

(1) Socrates is red

(2) $\operatorname{Red}_{1}$ is red

(1) attributes a quality (or a quality instance $)^{29}$ to a concrete particular of a standard sort (that is, a thicker particular), (2) attributes a quality to a quality instance. According to Moreland, what makes these two states-of-affairs generically different in terms of basic ontological structure is the type of relation involved in each. Borrowing from Husserl's terminology ${ }^{30}$ Moreland calls the relation distinctive of the state-of-affairs in (1) the moment/whole relation, and that distinctive of the state-of-affairs in (2) the being an essential property-constituent of relation (hereafter, the baep-c relation). ${ }^{31}$ The crucial issue here is whether or not there is a genuine difference-inkind between the state-of-affairs described in (1) and that described in (2). If there is, our puzzle simply won't arise for Moreland. If there is not, if the difference is a matter of degree rather than of kind, then the puzzle arises, and anyone wanting to be a traditional realist with regard to both quality instances and concrete particulars must solve it. What, then, are the distinguishing factors between the moment/ whole relation and the baep-c relation?

According to Moreland, a number of things are true of the baep-c relation which are not true of the moment/whole relation. First, in case (2), Red is necessary for red ${ }_{1}$ 's existence, but not vice versa; so the baep-c relation seems to exhibit an asymmetry of dependence whereby the (ontological) subject depends for its existence on the (ontological) predicate. However, neither Red nor red $_{1}$ is necessary for Socrates' existence; thus the moment/whole relation involves no such dependence relation. ${ }^{32}$ Second, Red is the essence of red $_{1}$, the

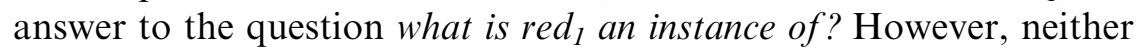
Red nor the moment red ${ }_{1}$ is the essence (in the sense described) of the whole, Socrates. Thus the baep-c relation makes a predicate essential to (in the sense of definitive of) a subject, whereas the moment/whole relation does not. Third, the "is" of sentence (2) is an "is" of classification, which "implies that red $_{1}$ is to be placed in the class of red instances, where "class" refers to a group of entities which literally share some entity in common." ${ }^{33}$ Sentence (2), Moreland says, means the same as " $\mathrm{red}_{1}$ is a red (that is, a red instance)." Though he does not explicitly say so, the implication is that the "is" of sentence (1) is 
not an "is" of classification; thus, apparently, the baep-c relation classifies (assigns its subject to a class) while the moment/whole relation does not.

These three differences are supposed to demonstrate a generic difference between the basic ontological structures of the respective states-of-affairs in (1) and (2) by showing that each involves a unique type of relation. However, these differences can be accounted for with perfect ease even on the view that both states-of-affairs are qualityindividuator complexes bound by predication, and hence that they have generically the same basic ontological structure - in other words, the view that quality instances are thinner particulars. In fact, the relative "thin-ness" of quality instances itself accounts for Moreland's first and second differences. The fact that Red is necessary for red ${ }_{1}$ 's existence while neither Red nor red ${ }_{1}$ are necessary for Socrates' existence is accounted for by the fact that red ${ }_{1}$ has only one property $^{34}$ while Socrates has many properties which fall into genus/ species hierarchies and other sorts of relations. Socrates is a spot. As such, Socrates has extension, shape, and color, among other properties. Thus it also must have more determinate properties - some determinate shape, some determinate, finite magnitude of extension, and some determinate color. But no determinate property will be necessary to its being a spot. The determinate color Red (or the quality instance which has it, $\operatorname{red}_{1}$ ) can be lost without affecting Socrates' existence precisely because Socrates has other less determinate properties (such as Color) which, being superior to Red in the genus/species hierarchy, allow for and partially govern the property exchange in respect of determinate color. In other words, the multiplicity of Socrates' properties, and the relations which obtain among them qua properties, account for their observable stratification into those essential to Socrates' existence and those accidental to it. ${ }^{35}$ This type of stratification is not possible for red $_{1}$ precisely because it has only one property. Consequently, every member of the set of $\operatorname{red}_{1}$ 's properties (all one of them) is equally important to red ${ }_{1}$ 's existence. In short, there is no hindrance to treating red $_{1}$ as a concrete particular with no accidental properties. The fact that it has no such properties does not demonstrate that it is not of the same basic ontological structure as a thicker concrete particular. The difference between Socrates and $\mathrm{red}_{1}$ in this respect is grounded in the difference in the number of properties each has, rather than a difference in the way each has its properties. 
The same considerations apply to Moreland's second difference. The reason "Red" is the answer to the question what is red an instance of? is that Red is the only thing that the concrete particular $\operatorname{red}_{1}$ is an instance of. $\operatorname{Red}_{1}$ is a relatively simple concrete particular, and this allows a relatively simple answer to the question what is red an instance of? Socrates is a more complex concrete particular, and the answer to the question what is Socrates an instance of? (if indeed such a question can be asked sensibly) ${ }^{36}$ cannot be given by naming one property. Socrates, insofar as it is an instance, is an instance of Red + Round + etc. That is, it is an instance of a combination of properties the likes of which is often called an essence. Indeed, just as a quality instance can be regarded as a thinner concrete particular, so can a thicker concrete particular be regarded as a multiple quality instance. So, while Red is not the whole answer to the question about Socrates, it is part of the answer. The fact that it is the whole answer to the question for red $_{1}$ and only part of the answer for Socrates does not show that red $_{1}$ and Socrates are generically different in respect of their basic ontological structure. This difference between them does not arise from their having their properties in different ways, but from their having different sets of properties; thus both may be regarded as property-individuator complexes bound by predication.

Finally, concerning the third alleged difference, the claim that the moment/whole relation does not assign its subject to a class while the baep-c relation does is plainly false. The "is" in "Socrates is red" would seem to locate Socrates in the class of red things (taking "thing" in a sufficiently broad sense) just as surely as "Red ${ }_{1}$ is red" locates red ${ }_{1}$ in the class of red things. Of course, sentence (1) does not place Socrates in the class of red instances, as sentence (2) does for red $_{1}$. But this difference is not due to a different sense of "is"; rather it is due to the fact that Socrates, as a thicker particular, is not merely an instance of any one property. Socrates' other properties dictate that it should be placed in the genus spot rather than the genus instance, and red $_{1}$ makes it into the latter genus only because it has but one property. Thus, insofar as there is a difference here, it is grounded in the difference in the number of properties bound by predication to the individuators in Socrates and red $_{1}$, respectively, and not a difference in the relations by which those properties are bound to their respective subjects.

In every case, then, the differences noted arise from the difference in the number and/or the identity of the properties had by Socrates 
and red $_{1}$, respectively, rather than from the way in which each has its properties. Since this is so, there is no compelling reason to think that the states-of-affairs described in (1) and (2) are generically different with regard to their respective ontological structures. And since the traditional realist account seems to portray quality instances as thinner concrete particulars, we must conclude that the puzzle does emerge, and that the traditional realist must deal with it. And this returns us to the suggestion that the mysterious part-whole/in-ness/ constitution/whole-moment relation should be treated as something other than a real relation.

To begin, let us consider how the part-whole "relation" differs from other relations. With most relations, the terms are wholly numerically distinct items - for example, a car and a house, a Father and a Son, two sheets of paper - and may be represented without confusion thus:

$$
\mathrm{T}_{1}-\mathrm{T}_{2}
$$

where $T_{1}$ and $T_{2}$ are the terms, and the line is the relation. Now one might innocently attempt to represent the part-whole relation between Socrates and quality instance red $_{1}$ on this model, thus:

$$
\text { Socrates }-\operatorname{Red}_{1}
$$

However, in the case of a part-whole relation, we do not have two wholly numerically distinct items joined by an extrinsic relation. Instead, one of the terms is inseparably present in the other. ${ }^{37}$ Thus, to construe the part-whole relation on this model is misleading, since to do so gives the impression of a sort of separateness which is not possible for the items involved. A less misleading representation of the part-whole relation between $\operatorname{red}_{1}$ and Socrates would look something like this:

$$
\left[\mathrm{P}_{1}-\mathrm{U}_{2}\right]+\left(\mathrm{U}_{1}-\mathrm{P}_{1}\right)-\left(\mathrm{U}_{1}-\mathrm{P}_{1}\right)
$$

This brings out the redundancy involved in the part-whole relation: $\operatorname{red}_{1}\left(\mathrm{U}_{1}-\mathrm{P}_{1}\right)$ must be mentioned twice in order to set the terms in relation to one another. The fact that there is redundancy involved suggests that this is not a case of genuine relation. What then could it be?

The notion of a relation of reason was introduced into Western philosophy by the great theologian-philosophers of the medieval period. ${ }^{38}$ Such a relation is a special type of being of reason, or ens mentis, and as such is a sort of mental construct: as Jeffrey Brower characterizes it, such a relation is "projected" into extra-mental 
reality by the activity of the mind. ${ }^{39}$ Moreover, Brower says, the relation of reason was employed, especially among later Medievals, "to clarify and explain a number of troublesome non-paradigmatic relational situations." 40 It seems to me that the part-whole "relation" analyzed above qualifies as just such a situation, and that the part whole relation should be treated as a relation of reason. But more can and should be said about this suggestion. Specifically, we need an account of how this phenomenon of mental creation and projection comes about. And here we find a ready answer in the closely connected but conceptually independent field of medieval research, the theory of distinctions.

A nice overview of medieval theories of distinction is given in Disputation VII of Francis Suarez' Disputationes Metaphysicae. According to Suarez, there are two main types of distinction: the real and the mental. By "real distinction", Suarez understands a sort characterized by mutual separablility, in the sense that items thus distinct can exist independently of one another. The most obvious examples of such items are concrete particulars; for instance, this man and that hat. Parts and wholes clearly are not distinct in this way. But consider the way Suarez describes the mental distinction, or distinction of reason. ${ }^{41}$ A mental distinction, he says, "does not formally and actually intervene between the things designated as distinct, as they exist in themselves, but only as they exist in our ideas," ${ }^{, 2}$ thus it obtains when "a single real entity [is] conceived according to various aspects," distinct as though they were distinct," 44 when it "conceives them as distinct through precisive abstraction whereby it effects, as it were, this type of distinction." tion" depends upon a distinction of this sort, since it is manifestly the case that it requires a single thicker particular to be set into relation with an inseparable, abstract part of itself, and obviously this is impossible in reality. How is this setting-into-relation to be done? It seems not only possible but also plausible that it might be accomplished by the sort of mental activity described by Suarez. First, the thicker particular is conceived according to various aspects: it is conceived as an unanalyzed whole; then, perhaps, as construed on Analysis 1, as a set of primitive entities which count as its ontological constituents: $\left\{\mathrm{P}_{1}, \mathrm{U}_{1}, \mathrm{U}_{2},-{ }_{1},-_{2}\right\}$. Second, through acts of abstraction, one isolates a subset of these primitive entities $\left\{\mathrm{U}_{1}, \mathrm{P}_{1},-{ }_{1}\right\}$ and conceives of them combined as they are in the thicker particular $\left(\mathrm{U}_{1}-\mathrm{P}_{1}\right)$, but in isolation from any conception of the thicker particular 
as a whole or its remaining constituents. This gets us the concept of a traditional realist quality instance, a thinner particular. Finally, one compares the conception of the quality instance with a conception of the concrete particular as a whole. In this way, one "conceives things which are not distinct as though they were distinct," and is thus tempted to construe quality instances and the thicker particulars to which they belong on the model of real relations.

Thus understood, the part-whole relation does not obtain in reality; it is a mental relation only, and it need not be included as an element in an adequate analysis of a thicker particular. I conclude, therefore, that Analysis 4 succeeds in solving the puzzle. ${ }^{46}$

It is unclear whether traditional realists of Moreland's ilk would find this view of the relation between Analyses 1 and 2 acceptable. On one hand, in addition to solving the puzzle, Analysis 4 succeeds in explaining some other aspects of Moreland's views. First, it clearly reveals why, on Moreland's view, a quality instance is taken to be "an inseparable part that cannot exist except as a constituent of a whole." ${ }^{47}$ On Analysis 4, a quality instance cannot be removed or separated from its whole intact for the simple reason that every quality instance of the same whole shares a part - one and the same bare particular. Thus, to remove one quality instance from all the others of the same whole would be to destroy all the others, and the whole along with them.

Second, in Issues and Options in Exemplification, Moreland initially presents his theory of quality instances in what seems to be an attempt at refuting Keith Campbell's claim that if a philosopher does not accept the identity of the referent of "the $F$ of $A$ " and "the $F$ of $B$ " then he must necessarily be a nominalist. ${ }^{48}$ Moreland's view allows him to maintain the position that descriptions of this sort can be used to refer to a number of different things, including qualities construed as universals and states-of-affairs such as traditional realist quality instances. If "the $F$ of $A$ " and "the $F$ of $B$ " are taken to refer to two quality instances, then, contra Campbell, "the two states-ofaffairs referred to are non-identical yet the position is clearly a realist one." 49

On a grammatical level, it seems rather odd to apply a locution of the form "the $F$ of $A$ " to a state-of-affairs. According to the ordinary 
sense of this type of locution, it would seem clearly to refer to a quality - in the case of "the redness of Socrates," the determinate color that belongs to Socrates. The color itself is not a state-of-affairs, but its being related to Socrates is. Thus, a locution such as "the being-red of Socrates" seems better suited to pick out a state-ofaffairs. ${ }^{50}$ Indeed, in order to grasp Moreland's sense when he uses "the redness of Socrates" to refer to one of his quality instances, it seems that one must have in mind Socrates on Analysis 4. This is made apparent by considering just what such a description would naturally be understood to pick out on the other Analyses. On Analysis 1, "the redness of Socrates" clearly picks out the universal Red, $\mathrm{U}_{1}$; thus the redness of Socrates is neither a complex entity or state-of-affairs, nor is it an inseparable or dependent part of the whole. On Analyses 2 and 3, "the redness of Socrates" clearly picks out the quality instance $\operatorname{red}_{1}\left(\left(\mathrm{U}_{1}-\mathrm{P}_{1}\right)\right.$ and $\left(\mathrm{U}_{1}-\mathrm{P}_{3}\right)$, respectively); and while red $_{1}$ is a state-of-affairs, it is not clear on Analyses 2 and 3 why it should be an inseparable or dependent part of a whole. Red $_{1}$ seems to be a whole unto itself, a this red. As such, it is conceivable that red might be detached from Socrates and attached to Plato or to some other thing capable of being red. Only with Analysis 4 in mind can one see how "the redness of Socrates," used idiosyncratically, might actually pick out states-of-affairs which are also dependent parts of wholes, as Moreland wants them to be.

On the other hand, Analysis 4 seems to be opposed to certain aspects of Moreland's view. For example, it seems to be inconsistent with his view that bare particulars do not unify concrete particulars. Indeed, it is hard to see how, on Analysis 4, the bare particular in Socrates could fail to play a unifying role, since it stands as the central hub of predication, so to speak - that is, it is being predicated of it that makes a set of qualities (and, by extension, quality instances) belong to one and the same concrete particular.

Also, Analysis 4 seems to undermine the legitimacy of Moreland's attempt to use the traditional realist view of quality instances as a rejoinder to Campbell's claim that, in order to avoid nominalism, one must accept the identity of the referent of "the $F$ of $A$ " and "the $F$ of $B$." Very likely, Campbell means these definite descriptions to be taken in their standard sense, according to which, as we have seen, they refer to qualities (which may then be construed as universals, as on Analysis 1, or tropes, as on Campbell's view). However, the sense in which one can deny the identity of the referents of "the $F$ of $A$ " and "the $F$ of $B$ " and not be a nominalist, which is illustrated by 
Analysis 4, is quite different from the sense in which Campbell's claim is made, which is illustrated by Analysis 1. The fact that one can imbue definite descriptions of the form "the $F$ of $A$ " with an idiosyncratic sense such that they refer to particular states-of-affairs does not show that Campbell is wrong in claiming that in order to avoid nominalism, one must accept the identity of the referent of "the $F$ of $A$ " and "the $F$ of $B$ " when such definite descriptions are intended in their standard sense. Thus, while it does flag the important linguistic point that descriptions of the form "the $F$ of $A$ " can be used in different ways, Moreland's observation seems to contain no ontological point which stands opposed to Campbell's claim.

The foregoing considerations call into question Analysis 4 as an interpretation of Moreland's views, but they do not call into question its success as a solution to the puzzle. Those aspects of Moreland's view to which Analysis 4 seems opposed are not essential to the traditional realist views in question considered in specie; rather, they are features peculiar to Moreland's own version of traditional realism.

There is still at least one worry that any traditional realist might have about Analysis 4. The process of making a mental distinction, itself the foundation of the mental part-whole relation, seems to require that we treat the quality instance itself as a mental construct. After all, as described at the end of section $2, \operatorname{red}_{1}$ is not a natural unity "there to be found" in Socrates, the way redness itself is; rather, it is only the artificial isolating of some of Socrates parts that gets us the concept of red ${ }_{1}$ as an entity capable of consideration in itself. Indeed, the business of "conceiving things which are not distinct as though they were distinct" would seem necessarily to involve a kind of falsification - and even Suarez describes the mental distinction as arising from "inadequate concepts of one and the same thing." 51 Does not the lack of adequacy imply that the concept of a quality instance is somehow spurious, that what it represents is a kind of mental fiction? Is not the quality instance, like its relation to its thicker particular, at best an ens mentis, and therefore not an ens reale? And, if this is the case, is this still a realist theory of quality instances?

Now it may be that, contrary to initial appearances, the strategy I have adopted in solving the puzzle does not commit us to the view that quality instances are mere entia rationis. Suarez speaks of a 
distinction that is called "mental" by some (though he ultimately thinks this is a misnomer), saying:

this type of mental distinction can be understood as pre-existing in reality, prior to the discriminating operation of the mind, so as to be thought of as imposing itself, as it were, on the intellect, and to require the intellect only to recognize it, but not to constitute it. In this acceptation of the term the distinction would be called mental rather than real only because it is not so great, and in itself not so evident as a real distinction, and hence would need attentive inspection by the mind to discern it. ${ }^{52}$

This mental distinction improperly so-called, he notes, is the same as what some medievals call a "distinction from the nature of the case," and what John Duns Scotus calls a "formal distinction." Now, in fact, there is significant descriptive overlap between the formal distinction and the mental distinction properly so-called, and this was enough for some of Scotus' early followers to interpret the formal distinction as a mere mental distinction. ${ }^{53}$ However, other of his early followers, as well as most of the contemporary commentators with which I am familiar, interpret the formal distinction as a third sort of distinction that is, as Suarez puts it, "greater than a mental distinction, but still not so great as the real distinction between thing and thing." ${ }^{54}$ On this interpretation, the formal distinction exists in reality prior to having any mental activity focused upon it, thus it is no mere mental distinction; and yet it fails to be a real distinction in the standard sense insofar as its terms are not capable of independent existence. Rather, the terms of a formal distinction are "essentially" or "definitionally" distinct. As the Catholic Encyclopedia has it: "A thing is 'formally distinct' when it is such in essence and in concept that it can be thought of by itself, when it is not another thing, though with that other it may be so closely united that not even omnipotence can separate it." ${ }^{55}$ Examples of things formally distinct according to Scotus include the divine attributes, the faculties of the human soul, and, most pertinent to the present discussion, a thing's common nature and its haecceity.

These latter concepts do not correspond exactly to any commonly employed in the contemporary debate about the ontology of concrete particulars, but they do have a kind of analogical connection. In itself, the common nature is a terribly mysterious entity, neither universal nor particular, neither one nor many, neither existent nor non-existent. Though in itself it does not exist, the common nature is supposed to be able to enter into existence in two ways, really or 
cognitionally. When the common nature acquires real existence, it becomes the individual essence of a substance, while entering into cognitional being yields a universal concept. ${ }^{56}$ On this view, then, universals never show up as the properties of things, as they do for contemporary realists. Moreover, though the common nature is not the same as a universal, it is arguably the closest analogue to what contemporary realists would call a universal, since it is the only thing that different substances truly have in common. Haecceity, on the other hand, is Scotus' special term for the individuating element in a substance; thus it serves an analogue for Moreland's bare particulars. Given these analogical relationships, it is reasonable to wonder whether something matching the description of the formal distinction might intervene between a quality instance and its thicker particular as these have been characterized above.

At first glance, it may seem that a quality instance can be considered in itself, and that its definition or essence does differ from that of its thicker particular. However, neither the separation in thought nor the difference in essence is complete. Even in thought, there is a necessary overlap between a quality instance and its thicker particular for the simple reason that they share a part - namely, the same bare particular. ${ }^{57}$ It is crucial to note that the inseparability here in question is not limited to the realm of "real" existence - as seems to be the case with the terms of a formal distinction - but is just as unavoidable in the realm of cognition. Whether we recognize it or not, the bare particular that we entertain in a thought of, say, red $_{1}$, is by definition and in essence, the bare particular of Socrates. ${ }^{58}$ Thus even in our most isolated thought of $\operatorname{red}_{1}$, there is still an implicit reference to Socrates. ${ }^{59}$

For this reason, then, it seems to me that the distinction between a quality instance and its thicker particular does not meet the requirements for a formal distinction. And since it is the case both that the distinction between them is clearly not a real distinction and that Suarez' descriptions of the mental distinction do seem to fit the phenomena involved quite precisely, it seems most correct to say that a mere mental distinction obtains between a quality instance and its thicker particular. And this seems to put us back in the position of viewing a Morelandian quality instance as an ens rationis.

Now, insofar as quality instances are construed as things that can stand in real relations to their thicker particulars - as Moreland often seems to do - I am inclined to treat them as mental constructs. However, this does not mean that they are wholly spurious, nor does 
it automatically disqualify the view from counting as realist. In support of this latter point, consider that, as noted in Section 1, the essence of the traditional realist view of quality instances is the appeal to universals in explanation of the apparent sameness involved in attribute agreement. On this criterion, even if the strategy I have suggested in solving the puzzle committed one to the view that quality instances are no more than mental fabrications, it could still count as a realist view of quality instances.

In support of the former point, that these concepts are not wholly spurious, consider Suarez' observation that a mental distinction of the type we are considering "arises not entirely from the sheer operation of the intellect, but from the occasion offered by the thing itself on which the mind is reflecting. ${ }^{\circ 60}$ What Suarez is getting at is that things can contain elements that serve as foundations for distinctions, but that these foundations themselves need not be distinctions. "Rather," he says,

the foundation must be either the eminence of the object which the mind thus distinguishes or at any rate it must be some reference to other things which are truly distinct in the real order, and with respect to which such a distinction is excogitated or conceived." 61

In the case of a quality instance, it would seem that reference to the individuator, the universal quality, and their binding relation - all of which are distinct in the real order ${ }^{62}-$ might well serve as an adequate foundation for the mental distinction between a quality instance and its thicker particular. Thus the notion of a quality instance is not wholly spurious. It is not a complete and utter fabrication, but is grounded in the authentic structure of a real entity, namely, the concrete particular.

\section{ACKNOWLEDGEMENTS}

This paper has benefited from conversations with Dallas Willard, David Kasmier, Gordon Knight, and from the comments of an anonymous referee for Axiomathes.

\section{NOTES}

\footnotetext{
1 "Red" is capitalized to indicate that it is being used as a name for a quality in general.

${ }^{2}$ Cf. Campbell (1997).
} 
3 The problems to which it purports to be a solution were, of course, first raised by Plato; see, for example, Plato's Parmenides and Brownstein (1973, Ch. 4).

${ }^{4}$ For discussion of the relevant issues in Aristotle, see Fine (1995), Lewis (1992), Reeve (2000), Scaltsas (1994), and Wedin (2000). On the Aristotelian tradition up through the middle ages, see Aaron (1952, Ch. 1), Boler (1963, Ch. 2), Gilson, (1949, especially Ch. 2), Maurer (1962), Owens (1956), Spade (1995), and Tweedale (1999).

5 The place of these issues in the Brentano school has been discussed in Smith (1994). For a presentation of the relevant interpretation of Husserl, see Moreland (1989b) as well as Willard (1964, 1984).

${ }^{6}$ For Moore's views, see Moore (1900-1901, 1923, 1953, especially chapters 18 20), as well as Brownstein (1973). For Stout's, see Stout (1923, 1936), and Seargent (1985). Additionally, chapter 1 of the Seargent text gives a brief historical sketch of some of the main ancient and medieval views vis-à-vis Stout's.

7 See Bergmann (1967), Allaire (1963), and Armstrong (1989). Discussions of recent upholders of the traditional realist view can be found in Moreland (1996, 2001).

${ }^{8}$ Moreland (1996, p. 142).

${ }^{9}$ Moreland (1996, p. 135).

${ }^{10}$ Moreland (1996, p. 135).

11 So called by Keith Campbell (cf. Campbell, 1997).

12 Ibid.

13 Cf. Moreland (1996, p. 140).

14 Allaire (1970, p. 235).

15 Moreland (1989a, p. 380) (my italics).

16 Moreland (1998, p. 254).

${ }^{17}$ Moreland (1996, p. 139).

18 For example, in Moreland (2001), he explains that the fact that Socrates is red "is best understood as follows: Socrates has a property instance, red $_{1}$, in it, and red $_{1}$ is red. The relation between $\operatorname{red}_{1}$ and Socrates is a sort of constituent/whole relation" (p. 98).

19 As Moreland characterizes it, in-ness/constitution is a relation of parts to the whole, not of parts to other parts of the whole.

20 The notion that the quality instances in question might share the same bare particular bears some similarity to Brentano's intriguing view that substances are included in accidents as their proper parts (see Smith, 1994, Ch. 3).

${ }^{21}$ Normally quality instances are called "abstract particulars" rather than "concrete particulars." This appellation is not meant to signify a difference in basic ontological structure (on the traditional realist view, they are still property-individuator complexes bound by predication, as are concrete particulars) but rather the fact that they are dependent entities which can be isolated only in abstractive thought.

22 Armstrong (1989, p. 60).

23 Moreland and Rae (2000, p. 71).

24 Moreland and Rae (2000, p. 71). 
25 Moreland and Rae (2000, p. 73).

26 Moreland and Rae (2000, p. 71).

27 Moreland (1998, p. 254).

28 Moreland (2001, pp. 98-100).

29 Moreland understands sentence (1) to mean the same as "Socrates has red ${ }_{1}$ as a constituent." It is debatable whether this is a natural way to understand sentence (1); nonetheless, for the sake of the argument, I'll not contest it here. I will, however, contest it later (see Section 3).

30 See, for instance, Husserl (1970, Investigation 3).

31 Note that neither of these relations is the relation of predication, strictly speaking. According to Moreland, predication in the strict sense belongs only to states-of-affairs involving an unanalyzable link between an individuator and a universal, the likes of which is described by the sentence: (3) "This (individuator) is red." On Moreland's view, states-of-affairs like (1) are grounded in states-of-affairs like (2), and states-of-affairs like (2) are grounded in states-of-affairs like (3).

32 Or if it does, it goes in the opposite direction. If the relation holds between Socrates and $\mathrm{red}_{1}$, then it would appear that the predicate depends on the subject. However, if the relation holds between Socrates and Red, then the relation would seem to involve a symmetrical relation of independence whereby neither of the relata depends essentially on the other

33 Moreland (2001, p. 99.)

34 Of course, the color Red may be analyzable into a number of sub-properties, such as hue, saturation, luminosity, and the like. In that case, it will be just those properties constitutive of Red that will be essential to red $_{1}$.

35 Indeed, insofar as "necessity to existence" is a distinguishing factor of the baepc relation, it would seem that "thicker" particulars can participate in it just as well as quality instances. "Aristotle is rational" fits the model of "Socrates is red," but unlike redness to Socrates, rationality is essential to Aristotle. Thus, even if the baepc relation is different from the whole/moment relation, it would seem to be a different species of the same genus of relation, as it does not signify a difference in basic ontological structure. Both quality instances and standard concrete particulars are still property-individuator complexes bound by predication, either essential or accidental.

${ }^{36}$ It would make sense to ask such a question if one accepted a doctrine of individual essences, as did many medievals and, on one interpretation, Aristotle. In that case Socrates would be an instance of Socrates-ness. On the notion of individual essences see, for Aristotle, Lewis 1984, and for various medieval thinkers, Maurer (1962), Boler (1963), Owens (1992), and Suarez (1947, pp. 26 ff).

37 The quality instance is inseparable from the thicker particular of which it is a constituent since the two share a part - namely, the same bare particular. So long as the quality instance exists, it cannot be separated from its thicker particular.

38 See Brower (2001). Brower notes that the notion seems to have been first used by Avicenna, and that it was popularized by Christian thinkers in the 13th and 14th centuries. 
39 Brower (2001, p. 21).

40 The cases Brower (2001) uses to illustrate this concept are ones in which there seems to be a relation grounded only in one of a pair of relata. The case in question here is different in that the relation has a ground in neither of its relata. Even so, the description quoted above does seem to capture the part-whole phenomenon here in question.

${ }^{41}$ More specifically, Suarez differentiates between two types of mental distinctions. First, there is a distinction of reasoning reason. This type of distinction has no ground in reality. For example, in noting that Peter is Peter, the distinction between subject and predicate is purely a product of the mind's activity. Secondly, there is the distinction of reasoned reason. This type of mental distinction can have a foundation in reality (see Suarez, 1947, p. 18; cf. Maurer, 1962, p. 361). It is the latter type that is being described here.

42 Suarez (1947, p. 18).

43 Suarez (1947, p. 19).

44 Suarez (1947, p. 18).

45 Suarez (1947, p. 18).

${ }^{46}$ It should not be assumed that my proposed use of the mental distinction is one Suarez would have accepted.

47 Moreland (1996, p. 142)

48 Moreland (1996, p. 134)

49 Moreland (1996, p. 143)

50 Moreland actually uses this type of locution elsewhere: "Assuming a realist construal of properties as universals, when some particular $a$ exemplifies a property $F$, the resulting state-of-affairs - $a$ 's being $F$ - is itself a particular" (Moreland 1998, p. 254).

${ }^{51}$ Suarez (1947, p. 19). As a paradigm of this type of distinction, Suarez gives the case of divine justice and divine mercy which, on the medieval understanding of God as ontologically simple, are supposed to be identical. A more common modern example is the distinction between Hesperus and Phosphorus (the evening star and the morning star). One notable difference between these cases and the one here under consideration is that, in each paradigmatic case, the two terms of the distinction are of the same "logical type" or "level of granularity" - two properties in the one, two substances in the other. In the case of a quality instance and its thicker particular, we have two items on different levels of granularity. This strikes me as an important difference, though its further implications (if any) are at present opaque to me. This difference notwithstanding, Suarez' descriptions of the mental distinction do seem to capture quite precisely the process by which a part-whole relation comes to be thought of; thus it seems reasonable to characterize this process as the making of a mental distinction.

52 Suarez (1947, p. 18).

53 cf. Suarez (1947, p. 24).

54 cf. Suarez (1947, p. 24). 
55 “Bl. John Duns Scotus", The Catholic Encyclopedia, Online Edition, URL= $<$ http://www.newadvent.org/cathen/05194a.htm > . Cf. Boler (1963, pp. 37-56) and Maurer (1962, pp. 229-236).

56 cf. Boler (1963, pp. 44-57), Owens (1992, pp. 154-156).

${ }^{57}$ It is not clear that this would be the case for Scotus, since it is unclear whether the haecceity is a structural part /constituent in just the way that a bare particular is supposed to be. For Scotus, the haecceity does not stand as the central hub of predication in a substance; rather it is the cause of what Scotus calls "contraction" which is the phenomenon (process?) responsible for particularizing the common nature in a substance.

${ }^{58}$ Insofar as we want to remain broadly Aristotelian in our realism, as many contemporary realists seem inclined to do, it is necessary to maintain that parts are what they are only relative to the wholes of which they are parts; thus the bare particular of Socrates is essentially a part of Socrates, and not primarily a part of $\operatorname{red}_{1}$. Any characterization of it as a part of $\operatorname{red}_{1}$ must be posterior, derivative, and subordinate to its characterization as a part of Socrates.

59 This is not to say that we must be aware of that reference - it can be there unnoticed. What I'm getting at here is what some authors have called "focal reference" or "focal meaning" (cf. Owens 1992, pp. 71-78).

60 Suarez (1947, p. 18).

${ }^{61}$ Suarez (1947, p. 18).

62 What kind(s) of distinction(s) might intervene among these entities is a worthy question, but one I cannot address here.

\section{REFERENCES}

Aaron, R. I.: 1952, The Theory of Universals, Oxford: Oxford University Press.

Allaire, E. B.: 1963, 'Existence, Independence, and Universals', in E. B. Allaire (ed.), Iowa Publications in Ontology, Vol. 1. Essays in Ontology, The Hague: Martinus Nijhoff , pp. 1-13.

Allaire, E. B.: 1970, 'Bare Particulars', in M. J. Loux (ed.), Universals and Particulars: Readings in Ontology, Notre Dame: University of Notre Dame Press, pp. 281-290.

Armstrong, D.: 1989, Universals: An Opinionated Introduction, Boulder: Westview Press.

Bergmann, G.: 1967, Realism: A Critique of Brentano and Meinong, Madison, Milwaukee, London: The University of Wisconsin Press.

Boler, J. F.: 1963, Charles Pierce and Scholastic Realism, Seattle: University of Washington Press.

Brower, J.: 2001, 'Medieval Theories of Relations,' in E. N. Zalta (ed.), The Stanford Encyclopedia of Philosophy (Summer 2001 Edition), URL $=<\mathrm{http}$ ://plato.stanford.edu/archives/sum2001/entries/relations-medieval/ > .

Brownstein, D.: 1973, Aspects of the Problem of Universals, Lawrence: University of Kansas Press.

Campbell, K.: 1997, 'The Metaphysic of Abstract Particulars', in Mellor and Oliver (eds.), Properties, Oxford: Oxford University Press, pp. 125-139. 
The Catholic Encyclopedia, Volume V, 'Bl. John Duns Scotus', Copyright (C 1909 by Robert Appleton Company, Online Edition Copyright (c) 2003 by K. Knight, $\mathrm{URL}=<$ http://www.newadvent.org/cathen/05194a.htm $>$.

Fine, G.: 1995, On Ideas: Aristotle's Criticism of Plato's Theory of Forms, Oxford: Oxford University Press.

Gilson, E.: 1949, Being and Some Philosophers, Toronto: Pontifical Institute of Medieval Studies.

Husserl, E.: 1970, Logical Investigations, 2 Vol., J. N. Findlay (tr.), New York: Humanity Books.

Lewis, F.: 1984, 'What is Aristotle's Theory of Essence?', Canadian Journal of Philosophy 10 (suppl), 89-131.

Lewis, F.: 1992, Substance and Predication in Aristotle, Cambridge: Cambridge University Press.

Maurer, A.: 1962, Medieval Philosophy, New York: Random House.

Moore, G. E.: 1900-1901, 'Identity', Proceedings of the Aristotelian Society, 103-127.

Moore, G. E.: 1923, 'Are the Characteristics of Particular Things Universal or Particular?' Proceedings of the Aristotelian Society, Suppl. Vol. 3 (reprinted in Moore's Philosophical Papers, New York: Collier Books 1962, pp. 17-32).

Moore, G. E.: 1953, Some Main Problems of Philosophy, London: George Allen \& Unwin.

Moreland, J. P.: 1989a, 'Keith Campbell and the Trope View of Predication', Australasian Journal of Philosophy 67(4), 379-393.

Moreland, J. P.: 1989b, 'Was Husserl a Nominalist?', Philosophy and Phenomenological Research, 49 (June), 661-674.

Moreland, J. P.: 1996, 'Issues and Options in Exemplification', American Philosophical Quarterly, 33(2) 133-147.

Moreland, J. P.: 1998, 'Theories of Individuation: A Reconsideration of Bare Particulars', Pacific Philosophical Quarterly, 79, 251-263.

Moreland, J. P.: 2001, Universals, Montreal and Kingston: McGill-Queen's University Press.

Moreland, J. P. and Rae, S. B.: 2000, Body and Soul: Human Nature and the Crisis in Ethics, Downers Grove: InterVarsity Press.

Owens, J.: 1956, Reportatio: The Essential and Accidental Character of Being, and the Historical Controversy Surrounding the Problem of the Real Distinction, unpublished manuscript, J. R. Catan (ed.), URL $=<$ http://pvspade.com/Logic/index.html > .

Owens, J.: 1992, Cognition: An Epistemological Enquiry, Houston: Center for Thomistic Studies.

Reeve, C. D. C.: 2000, Substantial Knowledge: Aristotle's Metaphysics, Indianapolis: Hackett.

Scaltsas, T.: 1994, Substances and Universals in Aristotle's Metaphysics, Ithaca: Cornell University Press.

Seargent, D: 1985, Plurality and Continuity: An Essay in G. F. Stout's Theory of Universals, Dordrecht, Boston, Lancater: Martinus Nijhoff Publishers.

Smith, B.: 1994, Austrian Philosophy: The Legacy of Franz Brentano, Chicago and La Salle: Open Court. 
Spade, P. V: 1995, History of the Problem of Universals in the Middle Ages: Notes and Text, unpublished course packet, URL $=<$ http://pvspade.com $/$ Logic/docs/univers.pdf $>$.

Stout, G. F. 1923, 'Are the Characteristics of Particular Things Universal or Particular?', Proceedings of the Aristotelian Society Suppl. Vol. 3.

Stout, G. F.: 1936, 'Universals Again.' Proceedings of the Aristotelian Society, 15.

Suarez, F.: 1947, On the Various Kinds of Distinctions (Disputationes Metaphysicae, Disputatio VII, de variis distinctionum generibus), Trans. Cyril Vollert, S. J., Milwaukee: S.T.D, Marquet University Press.

Tweedale, M. M.: 1999, Scotus vs. Ockham: A Medieval Dispute over Universals, 2 Vol., Lewiston, Queenston, Lampeter: The Edwin Mellon Press.

Wedin, M. V.: 2000, Aristotle's Theory of Substance: The Categories and Metaphysics Zeta, Oxford: Oxford University Press.

Willard, D.: 1964, Meaning and Universals in Husserl's Logische Untersuchungen. Madison: University of Wisconsin doctoral dissertation, available through University Microfilms, Ann Arbor, MI.

Willard, D.: 1984, Logic and the Objectivity of Knowledge, Athens, OH: Ohio University Press. 